\title{
a evasão de alunos
}

José Lino Oliveira Bueno,

Prof. do Depto de Psicologia

e Educação da FFCLRP : USP

\section{RESUMO}

A evasão de alunos é examinada levando-se em conta questōes ligadas à escolha profissional, às expectativas de realização pessoal e sucesso profissional geradas pelos cursos, às dificuldades de adaptação à vida universitária e à estrutura curricular. São apresentadas recomendaçōes de providências que possam afetar as motivações e atitudes dos alunos.

"Não era bem isto o que eu esperava da Universidade". Com esta frase a Prof Maria Alves Bruns, do Setor de Educação da FFCLRP, intitula sua Tese de Doutorado sobre escolhas profissionais de alunos de Psicologia. Examinando o discurso de alunos que desistiram, que permaneceram e que concluíram o curso, mostra, numa perspectiva existencial, que a escolha profissional é experienciada de um modo impessoal e inautêntico. $O$ tempo na Universidade é vivido como se fosse um jogo em que cabe aos jovens, de preferência sem muita interrogação, encaixarem suas experiências significativas aos propósitos do curso. As frustraçōes na busca de conhecimento, de identidade profissional e de compreensão da própria existência tendem a conduzir ao palavrório sobre o curso, que exime, estudantes e alunos, das responsabilidades. A concretude do mercado de trabalho, experienciada depois da formatura, conduz os jovens do sonho à realidade. Acaba o sonho da profissão liberal e o que sobra como oportunidade é encaixarem-se, agora, num mercado profissional institucionalmente determinado, para o qual não tiveram preparação nem condições de escolha pessoal (Bruns, 1992).

Assim, parece-nos importante que o fenômeno de evasão universitária deva ser compreendido enquanto centrado na escolha profissional de nossos jovens, envolvido nas possibilidades de um projeto pessoal de vida. Se há evasão, existem também os alunos que permanecem insatisfeitos no curso e, uma vez Exposição apresentada na Mesa Redonda sobre " A Evasão nos Cursos de Graduação da USP " coordenada por Prof. Dr. Celso de Rui Beisiegel, Pró-Reitor de Graduação, em 10 de Novembro de 1992, Reitoria da USP. 
diplomados, sentem-se desajustados na atividade profissional. Alheamento profissional dos que saem, dos que ficam e dos que se formam. Se consideramos todos estes casos como diferentes modos de afastamento e desligamento, os números de evasão universitária crescem enormemente.

As escolhas são, em grande parte, feitas ainda por volta dos 15 anos, pela exigência do direcionamento do curso secundário, equivalente a um preparatório para o vestibular. São raros os privilegiados que têm alguma chance de orientação vocacional durante a escola secundária. A Prof Angela Rozestraten, do Centro de Psicologia Aplicada da FFCLRP, mostra com dados de pesquisa que orientou sobre "Representações profissionais", que o conhecimento de estudantes secundaristas sobre profissões de $3^{\circ}$ grau é superficial, fragmentado e, em geral, diz respeito a aspectos pouco essenciais das profissōes (Rozenstraten, 1992a).

Por volta de 17 anos de idade, ao inscrever-se para os exames vestibulares, $o$ jovem tem que optar quase que definitivamente pela profissão que deverá influenciar os rumos de sua vida. Práticas de atendimentos, conduzidas sob supervisão da Prof Angela Rozenstraten, indicam que as escolhas são em geral idealizadas, baseadas em determinantes nem sempre relevantes. Escolhe-se, por exemplo, Medicina Veterinária porque gosta-se de bichos (Rozenstraten, 1992a). Uma vez aprovado nos exames vestibulares o estudante não terá mais grandes oportunidades de alterar a carreira. Ao se matricular no curso escolhido o aluno se depara com um currículo rígido. A definição profissional ocorre desde o primeiro semestre e o aluno não tem grandes chances de mudar de curso, mesmo que seja para cursos de áreas afins. Além disso, cursos que poderiam oferecer mais alternativas dentro da carreira freqüentemente se orientam por um conservadorismo: a psicologia clínica, por exemplo, permanece quase que como única opção para psicólogos, quando, na verdade, poder-se-ia estar formando profissionais voltados para instituiçōes (por exemplo, hospitais, empresas, escolas, forense), para publicidade e comunicaçōes, etc.

Estes aspectos acima descritos parecem se distribuir de modo mais ou menos homogêneo entre os diversos cursos e campi da universidade e podem explicar, em parte, a evasão que se dá nos primeiros anos dos cursos. As peculiaridades da FFCLRP, entretanto, com cursos nas áreas de ciências biológicas, exatas e humanas, em uma mesma escola, local e período, permitem uma análise que pode esclarecer outros fatores envolvidos na evasão e, possivelmente, implicados na escolha profissional do nosso estudante.

Entre os cursos de psicologia, biologia e química há diferenças especiais quanto às expectativas de realização e sucesso profissional que estes cursos geram. 
O exame das tabelas dos últimos vestibulares mostra que o prestígio social das carreiras está diretamente ligado à nota de corte do vestibular. A Prof' Angela Rozenstraten examinou, em sua Tese de Doutorado defendida em 1987, as representações profissionais de 960 estudantes de $5^{\mathrm{a}}$ série do $1^{\mathrm{Q}}$ grau à $2^{\mathrm{a}}$ série do $2^{2}$ grau. Utilizando instrumentos em forma de escalas, encontrou representações de àlgumas profissōes que incluíam traços altamente valorizados a um grupo de ocupações e traços, ao contrário, de baixo valor a outro grupo de ocupações. Por exemplo, eram atributos de Medicina, Engenharia e Direito: altos salários, inexistência de desemprego, inteligência elevada, dificuldade nos estudos, felicidade, riqueza. Em contraposição, eram atributos de Enfermagem, eletricista, escriturário: baixos salários, pouca felicidade, pobreza, pouca inteligência e desemprego (Rozenstraten, 1992b).

A falta de prestígio social de certas profissões reduz os incentivos para que estas sejam buscadas com persistência; o aviltamento salarial e as dificuldades de obter condições adequadas de trabalho levam os cursos de licenciatura e de bacharelado a serem considerados uma atividade secundária na ordem do reconhecimento social. As possibilidades limitadas de sucesso financeiro como empregados ou no magistério se mostram palpáveis já no início da vida universitária. Com chances limitadas de emprego, com falta de prestígio, de condições de trabalho, de sucesso financeiro, a realização profissional passa a ser apenas uma fantasia na cabeça dos estudantes de cursos que levam a profissōes com estas características (magistério secundário, empregados em áreas técnicas $\mathrm{e}$ de pesquisa, etc.); à primeira dificuldade, a evasão do candidato a estas profissões é a conseqüência natural.

Verificamos, por outro lado, que outras profissões continuam a alimentar expectativas de prestígio, realização profissional e sucesso financeiro. Embora psicólogos orientados para bacharelado e licenciatura sofram as mesmas limitações acima apontadas, há, no entanto, a possibilidade deles serem profissionais liberais, gerando no estudante uma expectativa de abrir sua própria clínica, de ter as condições de trabalho dependentes mais do seu próprio empenho e, quando reconhecido, garantir sucesso financeiro, prestígio social e realização profissional. A análise das possibilidades reais fica transferida para quando já se engajar profissionalmente; mas as expectativas podem manter o estudante de psicologia dentro do curso.

Ocorre, aqui, uma circularidade que tem a seletividade econômica como ponto de ligação: por estas características, estes cursos, tais como medicina, odontologia etc. passam a ser cada vez mais procurados, resultando numa seletividade na hora do vestibular que é principalmente econômica; com isso, 
dificuldades de adaptação que envolvem condições financeiras (moradia, viagens, compra de material, etc.) são mais facilmente superadas; as expectativas geradas por estas profissōes ou, até mesmo, o investimento já feito para vencer uma alta competitividade, mantém mais as ligaçōes dos alunos com os cursos. Mais alunos permanecem no curso, diante das dificuldades. Somente desajustamentos muito intensos ou uma atitude mais pessoal em termos de projeto de vida são capazes de levar à evasão do aluno insatisfeito. Os números de evasão durante o curso são pequenos. Mas nem porisso estes alunos podem ser considerados como mais ajustados e satisfeitos. Muitas vezes se mantém pelo peso das pressões sociais e familiares. Outras vezes, os problemas vão se manifestar após a formatura, diante das dificuldades reais de profissionalização ou de desempenho.

Outro conjunto de fatores ligados à evasão, e que não se pode negligenciar, são os oferecidos pelas dificuldades de adaptação. A entrada na universidade envolve um processo de mudança, em geral bastante significativa, para o adolescente. Há a dificuldade de adaptação à mudança de cidade, de uma metrópole cosmopolita para uma cidade média do interior, acarretando limitações, seja de um pequeno município para uma capital, acarretando ameaças. Há a dificuldade de adaptação à vida universitária. Deixa-se, na maioria das vezes, um colegial ou um cursinho com orientação rígida e meramente reprodutora de conhecimento para enfrentar uma universidade que exige iniciativa e exercícios de crítica, acarretando um choque; às vezes, a mudança se opera no sentido contrário, quando o aluno vem de um colegial dinâmico para enfrentar aulas expositivas sem nenhuma motivação, acarretando decepção. Há a dificuldade de adaptação ao currículo escolar. As expectativas quanto à profissão nem sempre são acompanhadas pelo estudante da avaliação dos requisitos exigidos e das aptidōes necessárias para a formação naquela profissão; ocorre freqüentemente a recusa de formação em ciências básicas, incompreensão quanto à exigência de formação científica, negligência quanto aos aspectos sociais envolvidos na profissão, etc (por exemplo, o estereótipo de psicologia difundido pela mídia, dificulta ao aluno a aceitação do rigor exigido pela disciplina e profissão). A estrutura dos cursos, por sua vez, apresenta empecilhos para a fácil inserção do estudante nas atividades de ensino. A Prof Marisa Japur, do Centro de Psicologia Aplicada da FFCLRP, descreve, no relatório parcial de uma ampla pesquisa sobre "Análise do Currículo", que estudantes, professores e ex-alunos, embora avaliando positivamente a atual estrutura curricular do curso de psicologia, apontam aspectos que comprometem sua eficiência: a "soberania" de decisão de cada docente sobre suas atividades de ensino, a ausência de um projeto comum de formação, a desorientação do aluno frente ao seu processo de formação, o baixo nivel de envolvimento de docentes e alunos com a efetividade do processo ensino/aprendizagem, a ausência de um 
processo sistemático de avaliação da formação propiciada pelo curso (Japur, 1992).

Assim, a evasão enquanto parte de uma questão mais ampla da escolha profissional não se contém em poucos aspectos, mas se caracteriza por um conjunto de fatores, que são multiplicativos e que vão definir as atitudes e motivações do estudante universitário. É possível que os mesmos fatores aqui apontados estejam atingindo desigualmente os estudantes dos diferentes cursos, num caso levando ao desligamento de alunos, em outro, não sendo capaz de atingir alunos que encontram em outros fatores sustentação para sua permanência na escola. $O$ que não significa que as dificuldades de adaptação e as falhas de escolha profissional que contribuem para a alta taxa de desligamento em alguns cursos não estejam presentes nos cursos de baixa taxa de desligamento, representando, portanto, problemas nas atividades de formação dos estudantes, a serem adequadamente diagnosticados e enfrentados pelos diversos cursos da universidade.

Como enfrentar estes problemas?

Trata-se de um fenômeno de evasão ou um caso de exclusão de alunos? A palavra evasão pode estar significando uma postura ativa do aluno que decide desligar-se por sua própria responsabilidade. A palavra exclusão implica na admissão de uma responsabilidade da escola e de tudo que a cerca por não ter mecanismos de aproveitamento e direcionamento do adolescente que se apresenta para uma formação profissionalizante.

Há, sem dúvida, fatores intra e extra-escolares atingindo a questão da permanência do aluno na universidade. Qual a nossa responsabilidade? $O$ que temos feito e podemos fazer para enfrentar os fatores intra-escolares? Serão somente estes fatores, mais próximos, os que devemos considerar, numa discussão sobre a evasão dos nossos alunos? Ou será que não cabe à universidade usar sua posição de liderança e ajudar a remover as dificuldades impostas especialmente pelos fatores externos?

\section{Recomendações gerais}

1- Elaborar projetos de aprimoramento dos cursos, levando-se em conta as expectativas de abrangência, eficiência e integração de currículos (cf. M.Japur, 1992). 
- Estruturar cursos de bacharelado orientados para pesquisas de ponta ou programas integrados. A nova estrutura do bacharelado em Psicologia da FFCLRP introduzida em 1993 procura contemplar estas necessidades.

- Adequar a estrutura curricular das licenciaturas ao atendimento das exigências específicas do ensino de $1^{\circ}$ e $2^{\circ}$ graus. Os Laboratórios de Ensino de Ciências e o Centro Integrado de Estudos de Química da FFCLRP têm oferecido subsídios para estruturas curriculares mais adequadas.

- Ampliar as alternativas de inserção no mercado de trabalho dos formados com atribuiçōes tecnológicas e de profissōes liberais. $O$ Departamento de Psicologia da FFCLRP está procurando reavaliar o leque de alternativas que poderão ser oferecidas na graduação, além de cursos de especialização e pós-graduação.

2 - Facilitar a flexibilidade de currículo que permita adaptações e maiores alternativas na escolha da carreira para o aluno já matriculado. A FFCLRP tem uma experiência de curso propedêutico, que funcionou de 1964 a 1971, em que o aluno fazia a opção pela carreira depois de um primeiro ano durante o qual tinha contacto com disciplinas de formação científica e humanista básicas. A experiência foi interrompida, especialmente por dificuldades burocráticas, mas sua avaliação é positiva e merece ser reconsiderada.

3 - Executar um projeto de ampliação de Centros de Vivência e de promoção cultural nos campi. As condições de vivência universitária para o estudante brasileiro são bastante deficientes. Enquanto uma cidade cosmopolita como São Paulo pode compensar em parte estas deficiências, no interior o problema se torna mais grave: os campi não têm centros de vivências adequados, as bibliotecas não têm a extensão e eficiência exigidas e são poucas as alternativas culturais. (Como índice do despreparo da universidade para a promoção cultura, o campus de Ribeirão Preto, com seis unidades, não tem sequer uma sala para apresentações de peças teatrais e de recitais, sendo estas realizadas em palcos improvisados na Capela). As Assessorias Culturais dos campi do interior precisam ser prestigiadas nas suas iniciativas. 
4 - Instalar, ampliar ou tornar mais eficientes os serviços de orientação do estudante, abrangendo os aspectos pessoais, didático-científicos, culturais e profissionais.

5 - Dar maior atenção ao mercado profissional para os estudantes.

- A Universidade não deve ignorar o mercado de trabalho, mas procurar influenciá-lo através de uma contribuição às diretrizes de uma política sócio-econômica e de prioridades na formação profissional. A relação com as autoridades deve ser consistente e permanente, uma oportunidade de oferecimento de propostas e de cobranças de políticas necessárias. A Universidade não se reduz a ser apenas formadora de mão-de-obra, mas ela exerce uma liderança através da atuação de seus membros na divulgação de suas pesquisas, na participação em comissões governamentais, nas assessorias a entidades representativas, em manifestações, etc. A Universidade pode valorizar a inserção dos profissionais por ela formados em programas que tenham respaldo em uma política sócio-econômica.

- Buscar uma valorização do ensino de $1^{2}$ e $2^{\circ}$ graus. A Universidade parece querer muitas vezes ignorar a crise neste setor e não tem sido capaz de antecipar as conseqüências desta crise sobre a própria Universidade, que já se manifesta tanto através de candidatos mal preparados para o vestibular quanto pelo desinteresse da inserção do licenciado na carreira docente de $1^{2}$ e $2^{\alpha}$ graus. Cabe à Universidade uma tomada de posição, um compromisso, através de atitudes concretas.

- Promover maior integração escola-comunidade, através de convênios e fundações, para maior aproveitamento dos profissionais formados. Estamos maduros para uma maior aproximação universidade-empresa, se a empresa tende a continuar buscando apenas serviços melhores e mais baratos na Universidade e os professores a buscar apenas complementos de baixos salários? A Universidade, nesta relação, deve ser promotora de pesquisa científica e tecnologia e não mera prestadora de serviços.

6 - Incentivar a formação de núcleos de pesquisa sobre orientação vocacional, profissional e educacional na Universidade, promovendo o conhecimento e desenvolvimento de experiências neste sentido, seja na Escola de Aplicação como em outras unidades de ensino ligadas às atividades da Universidade. 
7 - Valorizar a função docente na Universidade. Não se pode esperar grandes avanços na graduação se o ensino não for valorizado, pelo reconhecimento de suas atividades em concursos de progressão na carreira. Professor produtivo deve ser aquele que, além de suas atividades de pesquisa, é competente na produção do trabalho docente, diagnosticando, avaliando e promovendo a formação do estudante.

\section{Referências:}

Bruns, Maria A. de T. (1992). "Não era bem isto o que eu esperava da Universidade: um estudo de escolhas profissionais". Tese de Doutorado, Faculdade de Educação da Unicamp.

Japur, Marisa (1992). Análise do Currículo do Curso de Psicologia da FFCLRP-USP - Relatório Síntese. Ribeirão Preto, FFCLRP-USP.

Rozenstraten, Angela S. (1992a). Abordagem Psicossocial da Escolha Profissional. Trabalho apresentado na Mesa-Redonda "Orientação Vocacional - Diferentes Correntes", no VI Encontro Paranaense de Psicologia, Agosto, Curitiba.

Rozenstraten, Angela S. (1992b). Comportamento Vocacional. Texto de Curso ministrado no VI Encontro Paranaense de Psicologia, Agosto, Curitiba.

\section{ABSTRACT}

The problem of "dropping out" by students is examined, taking into account choice of profession, expectations regarding personal realization and professional success generated by the courses, as well as difficulties in adapting to university lifestyle and curricular structure. Recomendations are made to improve student attitude and motivation. 